\title{
Title: Embodied Education and Education of the Body: The Phenomenological Perspective
}

\author{
Authors: Denis Francesconi DPU-Danish School of Education, Copenhagen, Denmark; \\ Massimiliano Tarozzi Unibo-University of Bologna, Italy, and UCL - Institute of Education, \\ London, UK.
}

\begin{abstract}
The concept of Embodied Cognition (EC) includes a variety of approaches involving embodied, embedded, extended and enactive cognition (sometimes referred to as the 4Es) and it can offer meaningful contributions to educational research and practice, including the re-evaluation of the role of the body in educational experiences. To discuss the reciprocal relevance of EC and phenomenological pedagogy, in this paper we start by shortly reviewing the "disembodiment of Western culture" and the "disembodied school" model, we then outline the origins of the connection between EC and education, and we conclude by discussing embodied education in formal education context.
\end{abstract}

We argue that embodied education goes far beyond sensorimotor processes, physical exercise and motor skills. Adopting a phenomenologically oriented embodied cognition perspective means taking seriously the idea that cognition is always and necessarily grounded into a bodily dimension and that it has a complex phenomenological nature intertwined with emotional, affective, reflective dimensions. Education, particularly formal one, must be able to consider and promote such embodied mind.

\section{Introduction:}

In this paper, we focus on the phenomenological legacy to the embodied theory and some of its implication for education theory and practice. The paper is organized in the following sections: after a brief introduction about the disembodiment of Western culture, we address the conundrums of a "disembodied school". Then we provide two possible entangled answers to the problem of the 
disembody school model: (1) the body in Husserlian phenomenology and (2) the Embodied Cognition theory (EC). Finally, one example of what we call "embodied education" is provided: the body and the 'fields of experience' in early childhood education.

The very origin of the supremacy of logos in the western tradition can be traced back to John 1:1: "In the beginning was the Word, and the Word was with God, and the Word was God." How would our philosophical, spiritual and cultural tradition have evolved if the initial lines of the Gospel of John were "In the beginning was the body, and the body was with God, and the body was God"? The relevance and supremacy attributed to the Logos instead of to the Soma is a central point in Western civilization and tells us a lot about how we became what we currently are, and therefore about the nature of Western education (Galimberti 2017) .

It is hard to say what it would have been otherwise. For sure, we know how the body was disregarded since the beginning of Western philosophy, well before Christianity. In Plato's Republic, for instance, the body is considered nothing more than a tool for physical training for the education of the Guardians (Book 3.2, Cooper 1997) and the reinforcement of the character. In the Gorgias, the body (soma) is notoriously defined as the tomb (sema) of the being (Gorgias 493a, Cooper 1997). In order to pursue the true knowledge (Ideal Forms), the soul must abandon the body, which is nothing else than an obstacle or, following Socrates, even an "evil": "as long as we have the body, and the soul is contaminated by such an evil, we shall never attain completely what we desire, that is the truth" (Phaedo 66b, Cooper 1997).

These words echo those of Descartes on the importance of "clear and distinct ideas" (Descartes 1993), ideas that are not affected by sensations and emotions, which are unstable, unreliable, unmeasurable. The originator of modern dualism surely brings back the body to the philosophical discourse but only to place it in the realm of objects, an object among objects, which then can be easily inserted in the Cartesian axes.

At the end of $20^{\text {th }}$ century Michel Foucault (1976) nicely summarized centuries of Western 'forgetfulness of the lived body' (Leibvergessenheit) by stressing the lack of recognition of body knowledge. The body has always been regarded as an objective device, which can be subjected to discipline, control and punishment.

Against this tradition, the phenomenological movement had provided one of the first philosophical attempts to seriously consider the role of the body in human experience, later followed by the first scientific attempt in the science of the mind offered by Embodied Cognition (EC) theory. Both 
phenomenology and EC try to move forward from the mainstreaming Western tradition, which is deeply metaphysical, dualistic, materialistic as well as mentalistic. Not surprisingly this typical Western mind centrism (logocentrism), which nowadays has developed into a form of neurocentrism, has had visible impact in Western school theory and practice.

\section{Disembodied school}

All that is related to the body - movement, physicality, perceptions, and emotions - is marginalized within the modern formal education system, which promotes an abstract knowledge model, centred on the rational thinking, expressed through alpha-numeric symbols, preferably in the written form of a book.

It is not just a question of the marginalization of physical education, a problem that certainly exists and that recent reforms are trying to overcome by increasing physical education school time and by formalizing initial teacher education. More worrying is the prevailing physical education model which conceives the body as an object that must be maintained and preserved: a body-machine that must work well in all its mechanisms. As we will show later in this paper, this evokes the predominant notion of wellness and fitness diffused in the society for which sports and exercise are primarily aimed at aesthetic development or health promotion through active and healthy life styles. There is of course nothing wrong with this. But this also reinforces the body-machine idea and objectifies the material body as an outer and separate envelope wrapping the subjectivity.

We claim that the major problem of body forgetfulness in the mainstreaming learning idea across schools is the lack of recognition of corporeality throughout the whole educational process at school, the absence of a body knowledge entangled in all learning processes and the oblivion of experiential knowledge and perceptual and sensory forms within the context of formal education (Gamelli, 2011). School theory is far beyond the scope of this chapter ${ }^{1}$, which is essentially a theoretical contribution, we observe that the prevailing theory of learning in a neoliberal school system tends to reduce the learning process to the acquisition of know-how skills, immediately usable in a flexible labour marked and easily assessable through standardized tests. In contrast, the

\footnotetext{
${ }^{1}$ For a more comprehensive discussion of a theory of school from a phenomenological perspective grounded in Hegel, Langeveld and Fink, see Brinkmann, in press.
} 
body at school plays a role not only in the gym, but also in every school task - cognitive, experiential, in the socialization processes, and the education of emotions - and it requires children to confront with their bodies.

\section{Answer 1: The body in Husserlian Phenomenology}

How can practitioners recognize and re-evaluate the role of the body in educational settings? Which pedagogical theory can provide a theoretical framework different from the mind-centred mainstream? In this section, we argue that such theoretical horizon can be found in phenomenology since its very origins.

While the more sophisticated elaboration of the embodied nature of mind is certainly to be attributed to Merleau-Ponty, whose entire work revolves around the theme on how embodied human beings experience the world, the body-mind lived connection can be traced back to the early stages of Phenomenology.

According to Gallagher (2014) an analysis of embodied aspects of perception and cognition can be found in Husserl's early work, namely in his Lectures of 1907 Thing and Space (Husserl, 1907/1997). But this topic is mostly elaborated in Ideen II, where Husserl develops the well-known key distinction between Körper and Leib, then further developed in the 5th Cartesian meditation. Subsequently, a theoretical elaboration of the key distinction between Leib and Körper, even before Merleau-Ponty, is resumed by other phenomenologists such as Max Scheler (1954/1973) and Edith Stein (1964), among others. While in German language this distinction seems quite evident, it is not the same for other languages including English and Italian (see table 1). Here, Körper is translated as "objective body" or "body-as-object" with typical Heidegger hyphenation, whereas Leib is rendered as "lived body" or "body-as-subject". In the Italian first translation of Ideen 2, the translator chooses the Merleau-pontian version of "le corps propre" = il corpo proprio, own body vs. simple corps.

\section{German}

Körper

\section{Leib}

$\begin{array}{lll}\text { English } & \begin{array}{ll}\text { Objective body; body-as- } & \text { Lived-body; body-as-subject; } \\ \text { object } & \text { the flesh }\end{array}\end{array}$




\begin{tabular}{cll}
\hline French & $\begin{array}{ll}\text { Le corps; le corps objectif; le } \\
\text { corps matériel }\end{array}$ & $\begin{array}{l}\text { Le corps propre; corpe vivant; } \\
\text { le corps-chair; chair }\end{array}$ \\
\hline Italian & Corpo; corpo oggetto & Corpo proprio; corpo vivo \\
\hline Spanish & Cuerpo & Cuerpo propio \\
\hline Table 1 & & \\
\hline
\end{tabular}

The more recent Italian translation of Ideen chooses corpo vivo (=corpe vivant, lived body) or even la carne (la chair, the flesh). This distinction is fundamental as a premise of the embodied theory and for its implications on the educational level. On the one extreme lies the body-thing, the organism, the machine objectively existing in a world composed by other objects. This is the body, for instance, of the traditional Western medicine: disjointed from the mind, the material wrap of the mind from which it is constitutively detached, also defined as a "dead body" (Galimberti, 2017). It is the body that must be exercised, trained, aesthetically embellished, but also disciplined and controlled, morally inhibited, sometimes concealed and covered. On the opposite lies the lived body, the inseparable psycho-physical unity, the body I am, the perceiving (or experiencing) body, the agentive body that moves in action. In Husserl's words: "the means of any perception, is the organ of perception, necessarily participates in any perception" (Husserl, 1983, p. 453).

In the Ideen 2 (not by chance transcribed by Edith Stein), Husserl contends a vision of human as psycho-physical being, where body and psyche are entangled in a primary and inseparable way. Therefore, he radically overturns the way of understanding subjectivity as lived body and and conceptualizes the mind-body-world system as inseparable.

The body-subject lies pre-reflexive and pre-categorical in the Lifeworld (Lebenswelt): the field of sensitive and perceptual experiences that is given in a primary/genuine (originär) way. Here our body is essentially intentional; it is is characterized by a directedness toward the object", the natural disposition to orientate the subjective consciousness towards the object. Being genuinely open to the world, a lived-body finds in the world its correlation and its indispensable environment (Galimberti, 2017) and perceives objects around it in terms of the possibilities it has to interact with them. In this sense, the body itself is at the centre of our orientation within the world and at the very centre of every perceptual experience. 
Thus, the perception of things in the world is a form of primary knowledge about things that is both sensory and motoric, and therefore constitutively embodied. In the Lebenswelt, the body comprehends its world without having to go through symbolic representations. This form of original and pre-categorical knowledge is largely underestimated in schools, particularly in the current Western school system that is dominated by the neoliberal discourse and favours the abstract reflection that comes later.

To sum up our argument, according to a phenomenological view, the body can be regarded along the following perspectives which have substantive and relevant implications for education:

1) The body is the site of sensitive perception. What Husserl calls the aesthetic plan, is the unifying dimension of all sensitive perceptions. Merleau-Ponty indicates the primacy of perception to stress the constitutive role of perception in mental life.

2) The body is the field of lived experience (Erlebnis). The originating Life World where subjects make sense to the world because they are naturally open to it.

3) The body is the medium of the subject towards the other subjects. The body makes empathy (Einfühlung) happen, the recognition of the other as a subject. Hence, the body structures the intersubjective relationship, being communication and language.

Not to mention that the body is also where Eros and sexuality reside. The Italian phenomenologist Bertolini argued that every educational relationship has an erotic nature and highlighted implications, consequences and responsibilities (Bertolini, 1991). This phenomenological view of the body bears some significant pedagogical implications that have not been carefully developed until now. Here, we highlight two of them:

\section{- Sensitive perception}

Didactic activities aimed at the development of perceptual corporeality are fundamental, since education can be phenomenologically regarded as the process that promotes and develops the constitution of subjectivity in all its aspects (Bottero, 2002). They should not be reduced to a pure preparatory work for the most praiseworthy forms of cognitive and disciplinary activities, especially in secondary school; they should be thought as fundamental per se. Phenomenology differs from cultural psychology (Gardner, 2011), which simply advocates a recognition of body language in learning processes. Phenomenology considers the Leib as "the pre-categorical terrain where our relationship with the world is structured". The body allows the subject's perceptual life through 
which it expresses its inner consciousness. Hence the necessity of a sensorial education (Bertolini, 1988, p.112) which finds a fertile soil in the early childhood education, although constantly threatened by growing cognitivism even at this level of schooling.

- Lived experience

A second pedagogical implication is the focus on lived experience (Erlebnis). Phenomenological pedagogy places the notion of (lived) educational experience at the hearth of educational processes. Complex processes of formation of students' subjectivities, understood as lived-bodies, take place in their lived experiences. In education, the possibilities and the modes in which subjects/students understand or make sense (Sinngebung) through intentional acts to the world and to other individuals are more essential than facts, events, contents or objective realities. Therefore, a phenomenological pedagogy does not intend to discover the cosmic order behind the educational phenomena, but it addresses the intentional capacity of the subjects living in the world and therefore their ability to make sense of things, thus gaining an authentic understanding, not of the res, but of the cogitata.

Objects, facts, realities do not have meaning per se. According to Husserl, we only have an "inadequate evidence" of them. Objects can be understood as meanings for a consciousness depending on subjects' intentionality. Hence, experiential education, education of the gaze, inviting to learn how to know, to look authentically to the world throughout one's lived experience, is crucial.

From the phenomenological point of view, conceiving education as a lived experience does not mean to focus solely on the teaching-learning process by developing the most effective methods for transmitting content and measuring goals' achievement. It actually means highlighting the authentic - in Husserlian way - meaning of learning for a situated, incarnated subject/student, helping him to foster a critical perspective towards models of reality and learning.

In this vein, Bertolini supported the creation of educational contexts that serve to broaden children's fields of experience. Working with young offenders, he claimed that educators should support them in deconstructing their closed worldviews and accompany them in reconstructing new ones, positive and full of existential optimism by moving away from the usual intentional capacity and build new lived experiences.

This perspective recalls the idea of experiential learning in the broad sense according to the theoretical perspective of Dewey, but phenomenology goes further, since lived experience, 
constructed through lived-bodies, allows students to improve their ability to give meaning to the world and the knowledge to interpret it. Bertolini, following Husserl, maintains that the lived body, the psycho-physical dimension, is where the construction of subjectivity for "passive genesis" primarily happens. This is then complemented by the intentional acts that construct subjectivity for "active genesis". Therefore, the two educational processes must be seen as integrated and simultaneously cultivated.

4. Answer two: Embodied cognitive science: a phenomenologically driven cognitive science

The Embodied Cognition Theory as outcome of the encounter between phenomenology and cognitive science is another perspective which acknowledged the role of the body in human experience and in teaching-learning processes. Then, in the following section, we provide some examples of a body education, not only narrowed in the disciplinary boundaries of physical education.

Conceiving education as a lived experience leads not to focus solely on the teaching-learning processes, by developing the most effective methods for transmitting content and measuring achievements, but is aimed at highlighting the meaning of learning for subjects and to foster a critical perspective towards those models of knowledge univocally and objectively given.

A second answer to the disembodiment of education can be found in another phenomenological driven perspective: the so-called Embodied Cognition theory (EC) as outcome of the encounter between phenomenology and cognitive science.

Recalling the Gospel of John from the point of view of cognitive science, we should probably say "In the beginning was the brain". Cognitive science is a hybrid field of study that consists of many different disciplines in order to study the mind, its nature and functions. It emerged between the end of the " 40 s and the beginning of the " 50 s during a series of conferences called the "Macy conferences" (Gardner 2008). Mostly based on cybernetics and informatics, it aimed at contrasting behaviourism and it proposed for the first time the application of computer science to the study of the mind. The main theorists, among others, were Alan Turing, John von Neumann, and Norbert Wiener. At the same time, another root started to grow during those conferences thanks to the presence of Gregory Bateson and Margaret Mead. While Turing and von Neumann used the 
computer as a metaphor to describe the mind, Gregory Bateson, Margaret Mead, Humberto Maturana, James Gibson made use of more nature-based metaphors for the mind. Famous examples are books such as "Mind and Nature" and "Ecological Mind" by Bateson (1979; 2000 [1972]), "The Tree of Knowledge” by Maturana and Varela (1987), “The Embodied Mind” by Varela, Thompson and Rosch (2017 [1991], “The Ecological Approach to Visual Perception” by Gibson (2014 [1979]). These titles already say very much about epistemological and ontological assumptions made by early scholars in the field of cognitive science.

Traditional cognitive science is rooted in the Western tradition based on the Cartesian model of the mind. Cognitivism, the main paradigm at the beginning of its history, builds up the scientific study of the mind on internalist and symbolic assumptions, reducing all mental life to abstract and formal functions and non-contextual models of the world. These abstract models, in the radical cognitivism view, are stored in the brain and detached from real-life experiential contingencies. The computational approach is often associated with the neuro-reductionist view that human cognition is entirely realized and carried out by the central nervous system alone, without any major role of the body or environment. This view is exemplified by the famous "brain-in-a-vat" scenario (Putnam 1981; Thompson and Cosmelli 2011).

The history of the so-called "science of the mind" is well represented by the world-wide known educationalist and psychologist Howard Gardner in his book "The mind's new science: a history of the cognitive revolution" (2008). In this book, first published in 1985, he presents the history of cognitive science since its inception down to the beginning of the Nineties. Not surprisingly, he does not mention embodied cognition movement because at that time, it still was in its initial phase and it did not receive any large recognition. However, the roots of EC are antecedent to the Nineties.

The early connection between cognitive science and phenomenology, which then formed the EC, was initiated by Maurice Merleau-Ponty and Hubert Dreyfus. Nowadays, they are considered the founding fathers of EC (Gallagher and Zahavi 2007). In table 2, we show innovative ideas and main contributions that both Merleau-Ponty and Hubert Dreyfus brought to a phenomenologically driven cognitive science, which was later named embodied cognitive science: 


\begin{tabular}{l|ll} 
INNOVATIVE IDEAS & $\begin{array}{ll}\text { Scientific approach merged } \\
\text { with phenomenology }\end{array}$ & $\begin{array}{l}\text { Phenomenological approach to } \\
\text { cognitive science (especially to } \\
\text { Ase of scientific data for } \\
\text { phenomenological analysis } \\
\text { (e.g. phantom limb) }\end{array}$ \\
MAIN CONCEPTS & $\begin{array}{l}\text { Anti-reductionism } \\
\text { Le corps proper }\end{array}$ & $\begin{array}{l}\text { Intelligence without representation } \\
\text { Intentional arc }\end{array}$ \\
Primacy of perception & Preyfus model of skill acquisition \\
Table 2 & Phenomenological critics to AI
\end{tabular}

- Merleau-Ponty has probably been the first scholar combining scientific data of his time with the phenomenological reflection, especially on the topic of the body. The best example in this case is his famous analysis of the phantom limb condition (Merleau-Ponty, 2013).

- Following his line of work, Dreyfus bravely tried to connect continental and analytic philosophy by bringing phenomenology into American cognitive science in the ' 70 s and ' 80 s. He was a philosopher trained in phenomenology and working in the field of philosophy of mind, cognitive science and artificial intelligence. Initially, he received many professional and even personal attacks for his criticism of the artificial intelligence program. Only in the 90's his work started to be recognized. His most famous contributions are "What computers cannot do" (1979 [1972]) and, twenty years later, "What computers still can’t do" (1992). Important articles are "Mind over machine" (2000), "A five-stage model of the mental activities involved in directed skill acquisition" (Dreyfus and Dreyfus 1980), and "Intelligence without representationMerleau-Ponty's critique of mental representation. The relevance of phenomenology to scientific explanation." (Dreyfus 2002) All his work constituted a strong attack to the Artificial Intelligence program from the phenomenological viewpoint and a solid contribution to the foundation of Embodied Cognition.

Finally, in 1991, Francisco Varela, Evan Thompson and Eleanor Rosch published "The Embodied Mind. Cognitive Science and Human Experience". This book is the cornerstone for the EC and it is based on an unusual mix of four different main sources: complex system theory, evolution theory, 
phenomenology and Buddhism (fig. 1). One might have concerns about the theoretical solidity and consistence of such a mix of diverse approaches, however it seems to have worked out well considering the huge literature in and about EC nowadays available. EC today is indeed a wellestablished research paradigm within cognitive science and operates in many different disciplines and areas. Main scholars, among others, are Shaun Gallagher, Evan Thompson, Andy Clark, Alva Noe, and Dan Zahavi. None of them, however, explicitly works on education.

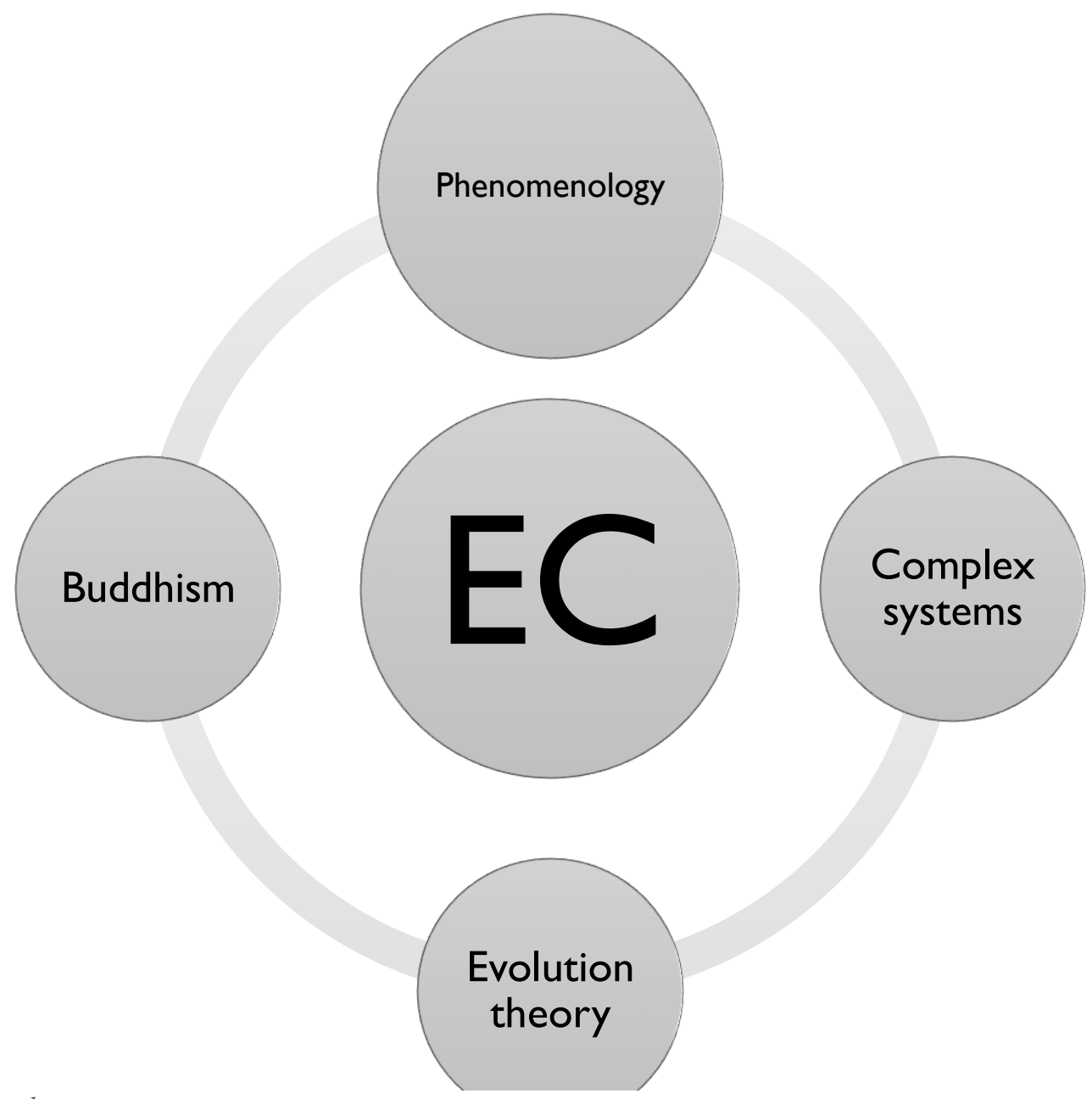

Figure 1

How EC and educational theory can merge is not the topic of our paper. While it is worth mentioning that a structural epistemological connection of EC and educational theory still does not exist, it is also relevant to mention a few initial attempts in this direction, for instance in Francesconi (2011), Francesconi and Tarozzi (2012), Gallagher and Francesconi (2012), 
Francesconi and Gallagher (2018). A special issue of the journal "Encyclopaideia" (2013) was also dedicated to such topics, including contributions made by scholars from different areas.

If the main research question that EC poses can be summarized as follows: "what is the role of the body in cognition?", then, from the educational point of view, the research question is "what is the role of the body in educational settings and processes?" With regards to this, EC has provided and is still providing an increasing amount of evidence about the role of the body in learning and school activities. The critique that EC proposes against standard mentalistic and neurocentric models of the mind is mostly based on the assumption that sensori-motor systems play a structural role in language production, perception and comprehension (Glenberg and Gallese 2012).

This has clear repercussions on education. Students of any age from K1 to K12 are requested to sit most of the time (Standal 2016). Starting with the ergonomics of the standard school model, critique must be raised about the way the body is conceived in class. In our schools, the body is basically expunged by the class experience, confined in the "desk-jail", limited, restricted, required to stay still, to not move. It is controlled as it is in the panopticon model (Foucault 1976).

However, it is now very clear that sitting too long during the day is dangerous for youngsters and adults, and reducing physical movement is troubling for health in general and for cognitive performances (Bidle et al. 2010). Some researchers assert that for learning, standing is much better than sitting (Mehta et al. 2015). The assumption that movement can facilitate learning is one of the biggest research areas of EC and solid evidences can be found in Juntunen and Leen Hyvonen (2004) and Glenberg and colleagues (2011). Beilock and colleagues (2015) even created what they call Action-based learning as learning intervention that aims at improving learning through bodily activities. The action-based theory of reading comprehension, for instance, asserts that the sensory and motor systems are involved during the process of understanding, imagining, and remembering an action described in a written story, as if the reader was actually perceiving or executing that action (Glenberg and Gallese 2012). Another classic example, particularly cited by sport psychologists (Beilock 2015), as evidence that neuro-cognitive functions and their bodily realizers must be studied together, is that reading comprehension and memory improve if the subject, while reading the descriptions of certain physical activities (e.g., baseball actions), performs physical manipulations that are consistent with them (Glenberg et al. 2011).

All these results and many others that are now piling up, suggest that we do not only need to get rid of the "brain-in-the-vat" hypothesis - the idea that the mind resides in the brain and that external factors such as body and environment play a minimal role - but also of the "body-on-the-chair" 
idea - the belief that to facilitate learning, movement must be basically prohibited in class and the body should be kept stationary. Therefore, this issue pertains also to researchers and scholars in the field of ergonomics and educational architecture. We believe that it is important to rethink our instructional spaces based on indications that come from EC and phenomenology. An EC approach to education promotes a new role of the body in educational settings, opens the class and the school, and helps dismantling the panopticon model that a modern school is. It is in this direction that EC completely supports, for instance, outdoor learning, experiential education and similar proposals.

It is true that the body plays a certain role in school systems, namely in physical education (PE). However, also physical education seems to adopt a reductionist approach to the body-mind connection and does not take into consideration phenomenological issues. We can now show two examples where the body is taken into consideration within educational settings, even if in a reductionist way: physical education and Embodied Learning.

\section{- Physical education}

Which kind of body does PE promote? The name already says everything: physical education or movement education. The semantic dimension described by the name, physical education (PE), seems to have had epistemological and even practical consequences on the work of physical education teacher by restricting their work to the mere physical dimension of the body, that is the Körper, and so excluding the Leib. This makes the tacit Cartesian and cognitivist assumptions of this approach absolutely clear. In PE the body-mind connection is reduced to the material (physical) and instrumental (movement) aspects. In this way, the body simply becomes an executor and servant of Her Majesty the Mind. Usually, educational goals in PE are sport performance, motor coordination, balance, strength, endurance, speed, sport rules acquisition, perhaps ethics in sport, maybe wellbeing. In PE, since its introduction in schools, the body is substantially considered in the mode of Körper, as an object, a tool among tools that can be implemented and perfectioned. In this way, PE at school can be easily compared to physical training in the military. Usually, in PE school's curricula there is little about relevant phenomenological topics such as body image, body schema, Leib and Körper. We argue that training programs for PE teachers based on EC and phenomenology should be implemented in order to prepare them at least about relevant EC and phenomenological concepts. In this way, we could support them in reconsidering the body-mind connection and adopting a less mechanical approach. 
- Embodied learning

A recent approach (Lindgren, Johnson-Glenberg, 2013) in cognitive science has been named Embodied Learning. This approach proposes to combine EC and learning science to teach math, physics and chemistry through bodily activities. Students are asked to enter virtual reality environment and play, for instance, with the planets and their orbits. The kinematic dimension of such embodied learning helps to improve memory retention and recall, thereby bettering school performances. However, this approach lies again on the body-as-tool perspective, where the body is used to reach higher cognitive competences (to learn school subjects) while the lived body is not considered at all. Once again, the phenomenological dimension is missing. This approach is valuable if it helps, as it seems, to learn better school knowledge and skills. The risk, however, is to replicate nothing else than the old abacus, where psychomotor games are functional to learn writing, reading or math skills. Indeed, still nowadays, reading, writing and arithmetic are the core skills of any school curriculum. By focusing mostly on learning instead of education as Bildung, the embodied learning approach is comparable to the standard cognitive learning approach where mentalistic, abstract, symbolic knowledge transmission prevails over the embodied, pragmatic and lived one. In Embodied Learning, body and movement are simply regarded as means to reach a superior cognitive goal. No educational activities are proposed to move beyond the natural attitude - natürliche Einstellung (HUA I, S. 53): phenomenologists describe the natural attitude as the attitude of taking an object as given, as such, in a naïve way, without the effort of an investigation on the phenomenal structure of the essence of that object as an object-for-an-embodied-subject. In the lived world, the world we all are in, which includes common sense and science, an object is always an object-for-someone, and the object-subject entanglement is such that considering an object as pure, disentangled from the observing and agent subject, can destroy the very nature of the object itself. A pure object is not reachable even in science, let apart in daily life. Formal school systems, as well as non-formal or informal education systems, tends to promote the natural attitude over the phenomenological one and this may undermine the importance of consciousness within formal schooling and the possibility for educational practitioners to work on the intentional consciousness.

In synthesis, in our perspective, these two areas - physical education and embodied learning - while they both enhance the role of the body, are missing two key phenomenological points:

- First, both are mainly focused on learning as instruction than education as Bildung. 
- Second, in both, the body is reduced to its factuality and functionality, as an object among other objects, as a useful tool to reach something else, either sport or school performance.

In this sense, it is important to point out the distinction between embodied education (Francesconi and Tarozzi 2012) and embodied learning (Lindgren and Johnson-Glenberg 2013). The first one is closer to the holistic view of education as in the Classical Greek tradition - Paideia - and Classical German tradition - Bildung. In these traditions, as well as in phenomenological education, a critical, enquiring and reflective mind capable of investigating the object-subject co-constitutive process is strongly promoted. Embodied learning, on the other side, is closer to the Anglophone analytical tradition of learning science, which considers cognitive learning over education to be the core of schoolwork.

\section{Examples: Kindergarten and "Fields of Experience"}

Right because the main scope of early childhood education is not learning abstract symbolic systems, cultural practices, theoretical forms of knowledge, it represents a good example of what we defined as embodied education. The attention paid to the bodily dimension in early childhood education and care in Italy has a long pedagogical tradition as well as a considerable history of public policies and early childhood services. Moreover, this approach has also extensively influenced primary school curriculum.

Back in the 1940s, Maria Montessori highly valued the sensorial work in schools she designed. The child, to her, is a "sensorial explorer" and her method "fully introduced movement education into the unique and inseparable whole education of the child's personality" (our translation (Montessori, 1942; p.62). Afterwards, from the 1960s and 1970s, some innovative experiences promoted by progressive municipalities transformed early childhood education from a social and welfare service to an educational one. Here, the educational role of body and movement have been central to the pedagogical project of these schools. First of all, learning spaces were designed in a creative and specialized way, as sites that allow the development of perceptual and sensory abilities. Second, ludic-expressive activities were taught to foster the full development of sensori-motor skills using various non-verbal languages (expressive and motion games, graphic-figurative, plasticmanipulative, mimic-gestural, sound activities). 
A worldwide known example of this approach (but not the only one) is the one used in the Reggio Emilia kindergarten. The so called "Reggio approach" focuses on the "hundred languages" belonging to every human being. Schools provide "atelier spaces" where children are offered daily opportunities to encounter many types of materials, many expressive languages, many points of view, working actively with hands, minds and emotions, in a context that values the expressiveness and creativity of each child in the group (Cagliari et al., 2016).

This approach is based on a clearly recognizable phenomenological assumption. Piero Bertolini, the main Italian phenomenological educational theorist (Tarozzi, 2017), who has been dealing with early childhood education for a long time, claimed that is important to empathically approach children's worldviews with the understanding that they are intentional subjects capable of making sense of the world, and consequently it is critical to design pedagogical contexts for them in which they are free to have meaningful experiences (Bertolini, 1984).

As a result, in the 1991 national law on early childhood education, largely inspired by this educational approach, curricular contents are not called "teaching subject", but they are expressed in terms of "fields of experience" or initially in "areas of experience" (Frabboni, 1980). Originally, there were three: body, environment, symbols. Today these areas have been reformulated in a more detailed form but always related to the original areas (see table).

$\begin{array}{lll}\text { Body } & \text { Self and other } & \text { Self and other }\end{array}$

\begin{tabular}{lll}
\cline { 2 - 3 } Environment & Body and movement & Body and movement \\
\hline & Space, order and measure & Knowledge of the world \\
\cline { 2 - 3 } & Things, time, nature \\
\hline Symbols & Messages, forms, media & Discourses and words \\
\hline & & Discourses and words
\end{tabular}




\section{Conclusions}

The problem we are dealing with in contemporary educational theory and practice, is probably not only the problem of the body in education, in cognitive science or in phenomenology. It is much more than that. It is the problem of the body in Western history and civilization. The mental-neurocentric science and society we are living in requires a deep reconsideration of its metaphysical roots in order to accept the body as Leib and not only as Körper. The phenomenological tradition, however, both at the origins and nowadays including EC, offers a horizon to support the necessary rethinking of the role of the body in our society, including education and school settings.

A phenomenological embodied education provides a new perspective. First, helps to move from the body-as-object idea to the lived body conception within the educational settings in order to promote a different education from PE; and secondly, it supports transforming educational experiences into lived experiences through the rediscovery and full acceptance of the sensori-motor nature of the mind, cultivating pre-categorical sensorial dimension of human experience.

In conclusion, following and paraphrasing once again the Gospel of John, we would like to be able, one day, to say that "In the beginning was the body" or, as in John 1:14 "the Word became flesh": that would finally mean the full acceptance of the embodied nature of the logos/mind. We are still far from that, but the educational effort will certainly help. We hope to contribute to go in this direction, toward an embodied mind in education.

\section{References}

Bateson, Gregory. (1979). Mind and nature: A necessary unity. New York: Dutton.

Bateson, Gregory. (2000). Steps to an ecology of mind: Collected essays in anthropology, psychiatry, evolution, and epistemology. University of Chicago Press.

Bertolini, Piero. (1988). L'esistere pedagogico: Ragioni e limiti di una pedagogia come scienza fenomenologicamente fondata. Firenze: La Nuova Italia. 
Bertolini, Piero. (1984). L'infanzia e la sua scuola. Firenze: La Nuova Italia.

Bertolini, Piero. (1991). L'eros in educazione. Considerazioni pedagogiche, in P. Bertolini, M.

Dallari (a cura di), Pedagogia al limite. La Nuova Italia: Firenze. Pp. 121 - 153.

Brinkmann, Malte (in press). Purposes of School - A Phenomenological Approach with Hegel, Langeveld and Eugen Fink. Phenomenology and Practice.

Cooper, John M.. (1997). Plato: Complete Works. Indianapolis: Hackett Publishing Company.

Descartes, René, Haldane, Elizabeth S., and Ross, George R. T. (1993, or. 1641). Meditations on first philosophy. London: Routledge.

Frabboni, Franco. (1980). Asilo nido e scuola materna. Firenze: La Nuova Italia.

Kontra, Carly, Lyons, Daniel J., Fischer, Susan M., and Beilock, Sian L. (2015) "Physical experience enhances science learning." Psychological science 26, no. 6: 737-749.

Biddle, Stuart JH, Pearson, Natalie, Ross, Gemma M., and Braithwaite, Rock (2010). Tracking of sedentary behaviours of young people: a systematic review. Preventive medicine 51.5: 345-351.

Bottero, Enrico. (2002). Sapere del corpo e prospettive didattiche. in L. Balduzzi. Voci del corpo: Prospettive pedagogiche e didattiche. Firenze: La nuova Italia.

Cagliari, Paola, Castagnetti, Marina, Giudici, Claudia, Rinaldi, Carina, Vecchi, Vea and Moss, Peter (2016). Loris Malaguzzi and the Schools of Reggio Emilia: A selection of his writings and speeches, 1945-1993. (Contesting Early Childhood). London: Routledge.

Chow, Jia Y., Davids, Keith, Button, Chris, Shuttleworth, Rick, Renshaw, Ian, and Araújo, Duarte. (2007). "The role of nonlinear pedagogy in physical education." Review of Educational Research $77(3), 251-278$.

Dreyfus, Hubert L. (1979). What computers can't do: The limits of artificial intelligence (Vol. 1972). New York: Harper \& Row.

Dreyfus, Hubert L. (2002) "Intelligence without representation-Merleau-Ponty's critique of mental representation. The relevance of phenomenology to scientific explanation." Phenomenology and the cognitive sciences 1.4: 367-383. 
Dreyfus, Stuart E., and Dreyfus, Hubert L. (1980). A five-stage model of the mental activities involved in directed skill acquisition. No. ORC-80-2. California University Berkeley Operations Research Centre.

Dreyfus, Hubert L. (1992). What computers still can't do: a critique of artificial reason. MIT Press.

Dreyfus, Hubert, Dreyfus, Stuart E., and Athanasiou, Tom. Mind over machine. Simon and Schuster, 2000.

Francesconi, Denis. (2011) "Pedagogia e neuroscienze cognitive in dialogo. L'esempio dell'esperienza corporea." Formazione \& Insegnamento. Rivista internazionale di Scienze dell'educazione e della formazione 1: 223-230.

Francesconi, Denis and Gallagher, Shaun. (2018). Embodiment and Sport Pedagogy. In Cappuccio, M. (ed.). The MIT Handbook of Sport Psychology. Cambridge, USA: MIT Press.

Francesconi, Denis and Tarozzi, Massimiliano 2012. "Embodied Education. A convergence of phenomenological pedagogy and embodiment.” Studia Phaenomenologica 12: 263-288.

Foucault, Michel (transl. Alcesti, Tarchetti) (1976). Sorvegliare e punire: nascita della prigione. Torino: Einaudi.

Galimberti, Umberto. (2017). Il corpo. (23a edizione). Milano: Feltrinelli.

Gallagher, Shaun. (2014). Phenomenology and Embodied Cognition. In Shapiro, Lawrence (ed.), Routledge Handbook of Embodied Cognition. (9-18). London: Routledge.

Gallagher, Shaun. (2012). On the possibility of naturalizing phenomenology. In Zahavi, Dan (ed.), The Oxford Handbook of Contemporary Phenomenology. Oxford University Press.

Gallagher, Shaun and Francesconi, Denis (2012). Teaching phenomenology to qualitative researchers, cognitive scientists, and phenomenologists. Indo-Pacific Journal of Phenomenology 12.sup3 : 1-10.

Gallagher, Shaun, and Zahavi, Dan (2007). The phenomenological mind: An introduction to philosophy of mind and cognitive science. Routledge.

Gamelli, Ivano. (2011). Pedagogia del corpo. Cortina. 
Gardner, Howard (2008). The mind's new science: A history of the cognitive revolution. Basic books.

Gardner, Howard (2011). Frames of mind: The theory of multiple intelligences. New York: Basic Books.

Gibson, James J. (1979). The ecological approach to visual perception: classic edition. Psychology Press, 2014.

Glenberg, Arthur M., and Vittorio Gallese (2012). "Action-based language: A theory of language acquisition, comprehension, and production." cortex 48.7 (2012): 905-922.

Glenberg, Arthur M., Andrew B. Goldberg, and Xiaojin Zhu (2011). "Improving early reading comprehension using embodied CAI." Instructional Science 39.1: 27-39.

Glenberg, Arthur M., Jessica K. Witt, and Janet Metcalfe (2013). "From the revolution to embodiment: 25 years of cognitive psychology." Perspectives on Psychological Science 8.5: 573585.

Husserl, Edmund (1907/1997). Thing and Space: Lectures of 1907. Trans. R. Rojcewicz.

Dordrecht: Kluwer Academic Publishers.

Husserl, Edmund (1983). Ideas pertaining to a Pure Phenomenology and to a Phenomenological Philosophy, First Book. Trans. F. Kersten. Dordrecht: Kluwer.

Husserl, Edmund (1950-2004). Husserliana. Gesammelte Werke. Van Breda, Herman, Ljsseling, Samuel, Bernet, Rudoph. Den Haag: Suhrkamp.

Juntunen, Marja-Leena, and Leena Hyvönen (2004). Embodiment in musical knowing: how body movement facilitates learning within Dalcroze Eurhythmics. British Journal of Music Education 21.2: 199-214.

Lindgren R. and Johnson-Glenberg M. (2013). Emboldened by Embodiment. Six Precepts for Research on Embodied Learning and Mixed Reality. Educational Researcher 42 (8).

Maturana, H. R. and Varela, F. J. (1987). The tree of knowledge: The biological roots of human understanding. New Science Library/Shambhala Publications. 
Mehta, Ranjana K., Ashley E. Shortz, and Mark E. Benden (2015). "Standing up for learning: A pilot investigation on the neurocognitive benefits of stand-biased school desks." International journal of environmental research and public health 13.1: 59.

Menary R. (Issue Editor) (2010). Special Issue: 4E Cognition: Embodied, Embedded, Enacted, Extended. Phenomenology and the Cognitive Sciences 9 (4).

Merleau-Ponty, M. (2013). Phenomenology of perception. Routledge.

Montessori, M. (1935/1942). Ginnastica. In Ead. Il metodo della pedagogia scientifica, Roma, 1935. Ripubblicato in M. Montessori, Educazione alla libertà. Antologia a cura di M.L. Leccese. Bari: Laterza, 1942.

Roth, Michael W. (2013). On the Birth of the Intentional Orientation to Knowledge.

Encyclopaideia: Journal of Education and Phenomenology, 37: DOI: 10.4442/ency_37_13_06.

Shapiro, Lawrence (2011). Embodied Cognition. London: Routledge.

Scheler, Max. (1954/1973). Formalism in Ethics and Non-Formal Ethics of Values. Evanton, IL: Northwestern Universit Press. Or. Ed. 1954 Der Formalismus in der Ethik und die materiale Wertethik.

Standal, Oyvind (2016). Phenomenology and Pedagogy in Physical Education. New York: Routledge.

Stein, Edith (1964). On the problem of Empathy. The Hague: Nijoff.

Tarozzi, Massimiliano (2017). Piero Bertolini and the Italian phenomenological movement in education. In M. Brinkmann, W. Lippitz, and U. Stenger (Eds.), Pädagogik - Phänomenologie; Verhältnisbestimmungen und Herausforderungen. Band 3 der Reihe "Phänomenologische Erziehungswissenschaft". Hrsg. v. Wiesbaden: Springer VS.

Tarozzi, Massimiliano, Francesconi, Denis (2013). Introduction to the Special Issue "Embodiment and pedagogy. Education between phenomenology and neurocognitive sciences". Encyclopaideia: Journal of Education and Phenomenology, 37: 11-16. DOI: 10.4442/ency_37_13_01.

Thompson, Evan. and Cosmelli, Diego (2011). Brain in a vat or body in a world? Brainbound versus enactive views of experience. Philosophical topics, 39(1), 163-180. 
Varela, Francisco J., Thompson, Evan, and Rosch, Eleanor. (2017 [1991]). The embodied mind: Cognitive science and human experience. MIT press.

Weare, Katherine (2002). Promoting mental, emotional and social health. A whole school approach. London: Routledge.

Zahavi, Dan (2009). Naturalized Phenomenology. In Gallagher, Shaun and Schmicking, Daniel (eds.), Handbook of Phenomenology and Cognitive Science. Springer. 